\title{
On a Singular Second-Order Multipoint Boundary Value Problem at Resonance
}

\author{
S. A. Iyase and O. F. Imaga \\ Department of Mathematics, Covenant University, PMB 1023, Ota, Ogun State, Nigeria \\ Correspondence should be addressed to O. F. Imaga; imaga.ogbu@covenantuniversity.edu.ng
}

Received 14 March 2017; Revised 28 April 2017; Accepted 4 May 2017; Published 11 June 2017

Academic Editor: Qingkai Kong

Copyright (C) 2017 S. A. Iyase and O. F. Imaga. This is an open access article distributed under the Creative Commons Attribution License, which permits unrestricted use, distribution, and reproduction in any medium, provided the original work is properly cited.

The aim of this paper is to derive existence results for a second-order singular multipoint boundary value problem at resonance using coincidence degree arguments.

\section{Introduction}

In this paper we derive existence results for the second-order singular multipoint boundary value problem of the form

$$
\begin{aligned}
x^{\prime \prime}(t) & =f\left(t, x(t), x^{\prime}(t)\right)+g(t), \quad 0<t<1, \\
x^{\prime}(0) & =0, \\
x(1) & =\sum_{i=1}^{m-2} a_{i} x\left(\xi_{i}\right),
\end{aligned}
$$

where $f:[0,1] \times \mathbb{R}^{2} \rightarrow \mathbb{R}$ is Caratheodory's function (i.e., for each $(x, y) \in \mathbb{R}^{2}$ the function $f(\cdot, x, y)$ is measurable on $[0,1]$; for a.e. $t \in[0,1]$, the function $f(t, \cdot, \cdot)$ is continuous on $\mathbb{R}^{2}$ ). Let $\xi_{i} \in(0,1), i=1,2, \ldots, m-2,0<\xi_{1}<\xi_{2}<\cdots<$ $\xi_{m-2}<1, a_{i} \in(0,1) i=1,2, \ldots, m-2$, and $\sum_{i=1}^{m-2} a_{i}=1$, where $f$ and $g$ have singularity at $t=1$.

In [1] Gupta et al. studied the above equation when $f$ and $g$ have no singularity and $\sum_{i=1}^{m-2} a_{i} \neq 1$. They obtained existence of a $C^{1}[0,1]$ solution by utilising the LeraySchauder continuation principle. In [2] $\mathrm{Ma}$ and O'Regan derived existence results for the same equation when $f$ and $g$ have a singularity at $t=1$ and $\sum_{i=1}^{m-2} a_{i} \neq 1$. They also utilised the Leray-Schauder continuation method. These results correspond to the nonresonance case. The purpose of this article is therefore to derive existence results for (1) when $\sum_{i=1}^{m-2} a_{i}=1$ (the resonance case) and when $f$ and $g$ have a singularity at $t=1$. We shall employ coincidence degree arguments in obtaining our results. In this case, the methods used in $[1,2]$ are not valid.

Research on singular differential equations is important because singular differential equations are useful in the modeling of many problems in the physical and engineering sciences; see [3].

In general singular boundary value problems can be difficult to solve because they may blow up near the singularity. The existence and multiplicity of solutions for second-order nonsingular boundary value problems have been extensively studied by many researchers. However to the best of our knowledge the corresponding problem for second-order differential equations at resonance and with a singularity had not received much attention in the literature. For recent results in these directions see [1, 2, 4-9] and references therein.

The rest of this paper is organised as follows. In Section 2, we present some definitions, lemmas, and theorems necessary for obtaining our main results. In Section 3, we derive some lemmas and the main theorem. In what follows we shall utilise the following assumptions:

(A0) For $\xi_{i} \in(0,1), i=1,2, \ldots, m-2,0<\xi_{1}<\xi_{2}<\cdots<$ $\xi_{m-2}<1$ and $\sum_{i=1}^{m-2} a_{i}=1$.

(A1) There exist $a(t), c(t) \in L^{1}[0,1]$ with $(1-t) a(t),(1-$ $t) c(t), b(t) \in L^{1}[0,1]$ and $|f(t, x, y)| \leq a(t)|x|+$ $b(t)|y|+c(t)$, a.e., $t \in[0,1],(x, y) \in \mathbb{R}^{2}$. 
(A2) $g:[0,1] \rightarrow \mathbb{R}$ is such that $\int_{0}^{1}(1-t)|g(t)|<\infty$.

\section{Preliminaries}

In this section we state some definitions, theorems, and lemmas that will be used in the subsequent section.

Definition 1. Let $X$ and $Z$ be real Banach spaces. One says that the linear operator $L: \operatorname{dom} L \subset X \rightarrow Z$ is a Fredholm mapping of index zero if $\operatorname{Ker} L$ and $Z / \operatorname{Im} L$ are of finite dimension, where $\operatorname{Im} L$ denotes the image of $L$.

As a result of Definition 1, we will require the continuous projections $P: X \rightarrow X, Q: Z \rightarrow Z$ such that $\operatorname{Im} P=\operatorname{Ker} L$, $\operatorname{Ker} Q=\operatorname{Im} L, X=\operatorname{Ker} L \oplus \operatorname{Ker} P, Z=\operatorname{Im} L \oplus \operatorname{Im} Q$, and $\left.L\right|_{\text {dom } L \cap K e r P}: \operatorname{dom} L \cap \operatorname{Ker} P \rightarrow \operatorname{Im} L$ is an isomorphism.

Definition 2. Let $L$ be a Fredholm mapping of index zero and $\Omega$ a bounded open subset of $X$ such that dom $L \cap \Omega \neq \phi$. The map $N: X \rightarrow Z$ is called $L$-compact on $\bar{\Omega}$, if the map $Q N(\bar{\Omega})$ is bounded and $K_{p}(I-Q)$ is compact, where one denotes by $K_{p}: \operatorname{Im} L \rightarrow \operatorname{dom} L \cap \operatorname{Ker} P$ the generalised inverse of $L$. In addition $N$ is $L$-completely continuous if it is $L$-compact on every bounded $\Omega \subset X$.

Theorem 3 (see [10]). Let L be a Fredholm operator of index zero and let $N$ be L-compact on $\bar{\Omega}$. Assume that the following conditions are satisfied:

(i) $L x \neq \lambda N x$ for every $(x, \lambda) \in[(\operatorname{dom} L \backslash \operatorname{Ker} L) \cap \partial \Omega] \times$ $(0,1)$.

(ii) $N x \notin \operatorname{Im} L$, for every $x \in \operatorname{Ker} L \cap \partial \Omega$.

(iii) $\operatorname{deg}\left(\left.Q N\right|_{\operatorname{Ker} L \cap \partial \Omega}, \Omega \cap \operatorname{Ker} L, 0\right) \neq 0$,

with $Q: Z \rightarrow Z$ being a continuous projection such that $\operatorname{Ker} Q=\operatorname{Im} L$. Then the equation $L x=N x$ has at least one solution in $\operatorname{dom} L \cap \bar{\Omega}$.

In what follows, we shall make use of the following classical spaces, $C[0,1], C^{1}[0,1], L^{1}[0,1]$, and $L^{\infty}[0,1]$. Let $A C[0,1]$ denote the space of all absolute continuous functions on $[0,1], A C^{1}[0,1]=\left\{x \in C^{1}[0,1]: x^{\prime}(t) \in\right.$ $A C[0,1]\}, L_{\text {loc }}^{1}[0,1]=\left\{x:\left.x\right|_{[0, d]} \in L^{1}[0, d]\right.$ for every compact interval $[0, d] \subseteq[0,1)\}$.

$A C_{\mathrm{loc}}[0,1)=\left\{x:\left.x\right|_{[0, d]} \in A C[0, d]\right\}$.

Let $Z$ be the Banach space defined by

$$
Z=\left\{y \in L_{\mathrm{loc}}^{1}[0,1):(1-t) y(t) \in L^{1}[0,1]\right\},
$$

with the norm

$$
\|y\|_{Z}=\int_{0}^{1}(1-t)|y(t)| d t .
$$

Let $X$ be the Banach space

$$
\begin{aligned}
X & =\left\{x \in C^{1}[0,1): x\right. \\
& \left.\in C[0,1], \lim _{t \rightarrow 1^{-}}(1-t) x^{\prime}(t) \text { exists }\right\},
\end{aligned}
$$

with the norm

$$
\begin{array}{r}
\|x\|_{X}=\max \left\{\|x\|_{\infty},\left\|(1-t) x^{\prime}(t)\right\|_{\infty}\right\} \\
\text { where }\|x\|_{\infty}=\sup _{t \in[0,1]}|x(t)| .
\end{array}
$$

We denote the norm in $L^{1}[0,1]$ by $\|\cdot\|_{1}$. We define the linear operator $L: \operatorname{dom} L \subset X \rightarrow Z$ by

$$
L x=x^{\prime \prime}(t)
$$

where $\operatorname{dom} L=\left\{x \in X: x^{\prime}(0)=0, x(1)=\sum_{i=1}^{m-2} a_{i} x\left(\xi_{i}\right)\right\}$ and $N: X \rightarrow Z$ is defined by

$$
N x=f\left(t, x(t), x^{\prime}(t)\right)+g(t) .
$$

Then boundary value problem (1) can be written as

$$
L x=N x .
$$

Lemma 4 (see [2]). Let $y \in Z$. Then

(i) $\int_{0}^{t} y(s) d s \in L^{1}[0,1]$.

(ii) $\lim _{t \rightarrow 1^{-}}(1-t) \int_{0}^{t} y(s) d s=0$.

Lemma 5. If $\sum_{i=1}^{m-2} a_{i}=1$ then

(i) $\operatorname{Ker} L=\{x \in \operatorname{dom} L: x(t)=c, c \in \mathbb{R}, t \in[0,1]\}$;

(ii) $\operatorname{Im} L=\left\{y \in Z: \sum_{i=1}^{m-2} a_{i} \int_{\xi_{i}}^{1} \int_{0}^{s} y(\tau) d \tau d s=0\right\}$;

(iii) $L:$ dom $L \subset X \rightarrow Z$ is a Fredholm operator of index zero and the continuous operator $Q: Z \rightarrow Z$ can be defined by

$$
Q y=\frac{e^{t}}{h} \sum_{i=1}^{m-2} a_{i} \int_{\xi_{i}}^{1} \int_{0}^{s} y(\tau) d \tau d s
$$

where $h=\sum_{i=1}^{m-2} a_{i}\left[e+\xi_{i}-e^{\xi_{i}}-1\right] \neq 0$.

(iv) The linear operator $K_{p}: \operatorname{Im} L: \rightarrow \operatorname{dom} L \cap \operatorname{Ker} P$ can be defined as

$$
K_{p} y=\int_{0}^{t} \int_{0}^{s} y(\tau) d \tau d s
$$

(v) $\left\|K_{p} y\right\|_{X} \leq\|y\|_{Z}$ for all $y \in Z$.

Proof. (i) It is obvious that

$$
\operatorname{Ker} L=\{x \in \operatorname{dom} L: x(t)=c, c \in \mathbb{R}\} .
$$

(ii) We show that

$$
\operatorname{Im} L=\left\{y \in Z: \sum_{i=1}^{m-2} a_{i} \int_{\xi_{i}}^{1} \int_{0}^{s} y(\tau) d \tau d s=0\right\} .
$$

$$
x^{\prime \prime}(t)=y(t)
$$


and we show that (13) has a solution $x(t)$ satisfying $x^{\prime}(0)=0$, $x(1)=\sum_{i=1}^{m-2} a_{i} x\left(\xi_{i}\right)$ if and only if

$$
\sum_{i=1}^{m-2} a_{i} \int_{\xi_{i}}^{1} \int_{0}^{s} y(\tau) d \tau d s=0
$$

Suppose (13) has a solution $x(t)$ satisfying $x^{\prime}(0)=0, x(1)=$ $\sum_{i=1}^{m-2} a_{i} x\left(\xi_{i}\right)$; then we obtain from (13) that

$$
x(t)=x(0)+\int_{0}^{t} \int_{0}^{s} y(\tau) d \tau d s
$$

and applying the boundary conditions we get

$$
\sum_{i=1}^{m-2} a_{i} \int_{0}^{\xi_{i}} \int_{0}^{s} y(\tau) d \tau d s=\int_{0}^{1} \int_{0}^{s} y(\tau) d \tau d s,
$$

since $\sum_{i=1}^{m-2} a_{i}=1$, and using (i) of Lemma 4 we get

$$
\sum_{i=1}^{m-2} a_{i} \int_{\xi_{i}}^{1} \int_{0}^{s} y(\tau) d \tau d s=0 .
$$

On the other hand if (14) holds, let $x_{0} \in \mathbb{R}$; then $x(t)=x_{0}+$ $\int_{0}^{t} \int_{0}^{s} y(\tau) d \tau d s$, where $y \in Z$ and $x^{\prime}(t) \in A C_{\mathrm{loc}}[0,1)$. Then from Lemma $4 \int_{0}^{t} y(\tau) d \tau \in L^{1}[0,1]$ and $\lim _{t \rightarrow 1^{-}}(1-t) x^{\prime}(t)$ $=\lim _{t \rightarrow 1^{-}}(1-t) \int_{0}^{t} y(\tau) d \tau=0$. Hence

$$
x^{\prime \prime}(t)=y(t) .
$$

(iii) For $y \in Z$, we define the projection $Q y$ as

$$
\mathrm{Q} y=\frac{e^{t}}{h} \sum_{i=1}^{m-2} a_{i} \int_{\xi_{i}}^{1} \int_{0}^{s} y(\tau) d \tau d s, \quad t \in[0,1],
$$

where $h=\sum_{i=1}^{m-2} a_{i}\left[e+\xi_{i}-e^{\xi_{i}}-1\right] \neq 0$.

We show that $Q: Z \rightarrow Z$ is well defined and bounded.

$$
\begin{aligned}
|Q y(t)| & \leq \frac{\left|e^{t}\right|}{|h|} \sum_{i=1}^{m-2}\left|a_{i}\right| \int_{0}^{1}(1-s)|y(s)| d s \\
& =\frac{1}{|h|} \sum_{i=1}^{m-2}\left|a_{i}\right|\|y\|_{Z}\left|e^{t}\right|, \\
\|Q y\|_{Z} & \leq \int_{0}^{1}(1-t)|Q y(t)| d t \\
& \leq \frac{1}{|h|} \sum_{i=1}^{m-2}\left|a_{i}\right|\|y\|_{Z} \int_{0}^{1}(1-t)\left|e^{t}\right| d t \\
& =\frac{1}{|h|} \sum_{i=1}^{m-2}\left|a_{i}\right|\|y\|_{Z}\left\|e^{t}\right\|_{Z} .
\end{aligned}
$$

In addition it is easily verified that

$$
Q^{2} y=Q y, \quad y \in Z .
$$

We therefore conclude that $Q: Z \rightarrow Z$ is a projection. If $y \in \operatorname{Im} L$, then from (14) $Q y(t)=0$. Hence $\operatorname{Im} L \subseteq \operatorname{Ker} Q$. Let $y_{1}=y-Q y$; that is, $y_{1} \in \operatorname{Ker} Q$. Then

$$
\begin{aligned}
& \sum_{i=1}^{m-2} a_{i} \int_{\xi_{i}}^{1} \int_{0}^{s} y_{1}(\tau) d \tau d s \\
& =\sum_{i=1}^{m-2} a_{i} \int_{\xi_{i}}^{1} \int_{0}^{s} y(\tau) d \tau d s-\frac{1}{h} \sum_{i=1}^{m-2} \int_{\xi_{i}}^{1} \int_{0}^{1} y(\tau) d \tau d s \\
& \quad \cdot h=0 .
\end{aligned}
$$

Thus, $y_{1} \in \operatorname{Im} L$ and therefore $\operatorname{Ker} Q \subseteq \operatorname{Im} L$ and hence $Z=$ $\operatorname{Im} L+\operatorname{Im} Q=\operatorname{Im} L+\mathbb{R}$. It follows that since $\operatorname{Im} L \cap \mathbb{R}=\{0\}$, then $Z=\operatorname{Im} L \oplus \operatorname{Im} Q$. Therefore

$$
\operatorname{dim} \operatorname{Ker} L=\operatorname{dim} \operatorname{Im} Q=\operatorname{dim} \mathbb{R}=\operatorname{codim} \operatorname{Im} L=1 .
$$

This implies that $L$ is Fredholm mapping of index zero.

(iv) We define $P: X \rightarrow X$ by

$$
P x=x(0),
$$

and clearly $P$ is continuous and linear and $P^{2} x=P(P x)=$ $P x(0)=x(0)=P x$ and $\operatorname{Ker} P=\{x \in X: x(0)=0\}$. We now show that the generalised inverse $K_{p}: \operatorname{Im} L \rightarrow \operatorname{dom} L \cap \operatorname{Ker} P$ of $L$ is given by

$$
K_{p} y=\int_{0}^{t} \int_{0}^{s} y(\tau) d \tau d s .
$$

For $y \in \operatorname{Im} L$ we have

$$
\left(L K_{p}\right) y(t)=\left[\left(K_{p} y\right)(t)\right]^{\prime \prime}=y(t)
$$

and for $x \in \operatorname{dom} L \cap \operatorname{Ker} P$ we know that

$$
\begin{aligned}
\left(K_{p} L\right) x(t) & =\int_{0}^{t} \int_{0}^{s} x^{\prime \prime}(\tau) d \tau d s \\
& =\int_{0}^{t}(t-s) x^{\prime \prime}(s) d s \\
& =x(t)-x^{\prime}(0) t-x(0)=x(t)
\end{aligned}
$$

since $x \in \operatorname{dom} L \cap \operatorname{Ker} P, x(0)=0$, and $P x=0$.

This shows that $K_{p}=\left(\left.L\right|_{\operatorname{dom} L \cap \operatorname{Ker} P}\right)^{-1}$.

(v)

$$
\begin{aligned}
\left\|K_{p} y\right\|_{\infty} & \leq \max _{t \in[0,1]} \int_{0}^{t}(t-s)|y(s)| d s \\
& \leq \int_{0}^{1}(1-s)|y(s)| d s \leq\|y\|_{Z}, \\
\left\|(1-t)\left(K_{p} y\right)^{\prime}\right\|_{\infty} & \leq \max _{t \in[0,1]} \int_{0}^{t}(1-s)|y(s)| d s \\
& \leq\|y\|_{Z} .
\end{aligned}
$$


We conclude that

$$
\left\|K_{p} y\right\|_{X} \leq\|y\|_{Z}
$$

Lemma 6. The operator $N: X \rightarrow Z$ defined by

$$
N x(t)=f\left(t, x(t), x^{\prime}(t)\right)+g(t), \quad t \in(0,1)
$$

is L-completely continuous.

Proof. Suppose $\Omega$ is an open bounded subset of $X$. Let $R_{1}=$ $\sup \left\{\|x\|_{X}: x \in \Omega\right\}$. From condition (A1) and each $x_{n} \in \Omega$ we have

$$
\begin{aligned}
\left|N x_{n}(t)\right| & \leq\left|f(t), x_{n}(t), x_{n}^{\prime}(t)\right|+|g(t)| \\
& \leq a(t) R_{1}+b(t) \frac{R_{1}}{1-t}+r(t)+|g(t)| \\
& =\varphi(t) .
\end{aligned}
$$

We can deduce from (A1) and (A2) that $\varphi(t) \in Z$ :

$$
\begin{aligned}
\left|Q N x_{n}(t)\right| & =\left|\frac{e^{t}}{h} \sum_{i=1}^{m-2} a_{i} \int_{\xi_{i}}^{1} \int_{0}^{s} N x_{n}(\tau) d \tau d s\right| \\
& \leq \frac{1}{|h|} \sum_{i=1}^{m-2}\left|a_{i}\right| \int_{0}^{1}(1-s)\left|N x_{n}(x)\right| d s\left|e^{t}\right| \\
& \leq \frac{1}{|h|} \sum_{i=1}^{m-2}\left|a_{i}\right| \int_{0}^{1}(1-s)|\varphi(s)| d s\left|e^{t}\right| \\
& \leq \frac{1}{|h|} \sum_{i=1}^{m-2}\left|a_{i}\right|\|\varphi\|_{Z}\left|e^{t}\right|, \quad t \in(0,1), \\
\left\|Q N x_{n}\right\|_{Z} & \leq \frac{1}{|h|} \sum_{i=1}^{m-2}\left|a_{i}\right|\|\varphi\|_{Z} \int_{0}^{1}(1-t)\left|e^{t}\right| d t \\
& =\frac{1}{|h|} \sum_{i=1}^{m-2}\left|a_{i}\right|\|\varphi\|_{Z}\left\|e^{t}\right\|_{Z} \cdot
\end{aligned}
$$

This shows that $Q N(\bar{\Omega})$ is bounded in $Z$ and $Q N$ is continuous by using the Lebesgue Dominated Convergence Theorem. Next we show that $K_{P, Q} N(\bar{\Omega})=K_{P}(I-Q) N(\bar{\Omega})$ is compact.

By using (31) we derive

$$
\begin{aligned}
\left|K_{P} N_{n}(t)\right| & \leq \int_{0}^{t}(t-s)\left|N x_{n}(s)\right| d s \\
& \leq \int_{0}^{1}(1-s)|\varphi(s)| d s=\|\varphi\|_{Z},
\end{aligned}
$$

$$
\begin{aligned}
\left|N x_{n}(t)-Q N x_{n}(t)\right| & \leq\left|N x_{n}(t)\right|+\left|Q N x_{n}(t)\right| \\
& \leq|\varphi(t)|+\frac{1}{|h|} \sum_{i=1}^{m-2}\left|a_{i}\right|\|\varphi\|_{Z}\left|e^{t}\right| \\
& =\alpha_{r}(t), \\
\left|K_{P, Q} N x_{n}(t)\right| & =\left|K_{p}\left(N x_{n}-Q N x_{n}\right)(t)\right| \\
& \leq K_{P} \alpha_{r}(t) \leq\left\|\alpha_{r}\right\|_{Z} .
\end{aligned}
$$

This indicates that the sequence $\left\{K_{P, Q} N x_{n}(\bar{\Omega})\right\}$ is uniformly bounded in $C[0,1]$. Also for $t \in[0,1)$

$$
\begin{aligned}
& \left|(1-t)\left(K_{P, Q} N x_{n}\right)^{\prime}(t)\right| \\
& \quad=\left|(1-t) \int_{0}^{t}\left(N x_{n}(s)-Q N x_{n}(s)\right) d s\right| \\
& \quad \leq \int_{0}^{1}(1-s) \alpha_{r}(s) d s \leq\left\|\alpha_{r}\right\|_{Z} .
\end{aligned}
$$

Hence the sequence $K_{P, Q} N x_{n}(t)$ is bounded in $C[0,1]$ and $\lim _{t \rightarrow 1^{-}}(1-t)\left(K_{P, Q} N x_{n}\right)^{\prime}(t)=0$. Thus $K_{P, Q} N x_{n}(t)$ is bounded in $X$.

Next we show that the sequence $\left\{K_{P, Q} N x_{n}(t)\right\}$ is equicontinuous. Let $t_{1}, t_{2} \in[0,1], t_{1}<t_{2}$; then

$$
\begin{aligned}
& \left|K_{P, \mathrm{Q}} x_{n}\left(t_{2}\right)-K_{P, \mathrm{Q}} x_{n}\left(t_{1}\right)\right|=\left|\int_{t_{1}}^{t_{2}}\left(K_{P, \mathrm{Q}} N x_{n}\right)^{\prime}(s) d s\right| \\
& \quad \leq \int_{t_{1}}^{t_{2}} \int_{0}^{s}\left|\left(N x_{n}(\tau)-\mathrm{Q} N x_{n}(\tau)\right)\right| d \tau d s \\
& \quad \leq \int_{t_{1}}^{t_{2}} \int_{0}^{s} \alpha_{r}(\tau) d \tau d s,
\end{aligned}
$$

for every $t_{1}, t_{2} \in[0,1]$. By (i) of Lemma $4 \int_{0}^{s} \alpha_{r}(\tau) d \tau \in$ $L^{1}[0,1]$. Thus the sequence $\left\{K_{P, Q} N x_{n}(t)\right\}$ is equicontinuous on $[0,1]$ and by Arzela-Ascoli Theorem is convergent. Next we prove that the sequence $\left\{(1-t)\left(K_{P, Q} N x_{n}\right)^{\prime}\right\}$ is also equicontinuous on $[0,1]$. We have for $t \in[0,1]$

$$
\begin{aligned}
& \left|\left[(1-t)\left(K_{P, Q} N x_{n}\right)^{\prime}(t)\right]^{\prime}\right| \\
& \quad=\left|-\left(K_{P, Q} N x_{n}\right)^{\prime}(t)+(1-t)\left(K_{P, Q} N x_{n}\right)^{\prime \prime}(t)\right| \\
& \quad \leq\left|\int_{0}^{t}\left(N x_{n}(s)-Q N x_{n}(s)\right) d s\right|+\left|(1-t) N x_{n}(t)\right| \\
& \quad \leq \int_{0}^{t} \alpha_{r}(s) d s+(1-t) \varphi(t)=\psi(t) .
\end{aligned}
$$


Using (i) of Lemma 4 and the fact that $\alpha_{r}(t)$ and $\varphi(t)$ are in $Z$ we conclude that $\psi(t) \in L^{1}[0,1]$. Therefore

$$
\begin{aligned}
& \left|\left(1-t_{2}\right)\left(K_{P, Q} N x_{n}\right)^{\prime}\left(t_{2}\right)-\left(1-t_{1}\right)\left(K_{P, Q} N x_{n}\right)^{\prime}\left(t_{1}\right)\right| \\
& \quad=\left|\int_{t_{1}}^{t_{2}}\left[(1-s)\left(K_{P, Q} N x_{n}\right)^{\prime}(s)\right]^{\prime} d s\right| \\
& \quad \leq \int_{t_{1}}^{t_{2}}\left|\left[(1-s)\left(K_{P, Q} N x_{n}\right)^{\prime}(s)\right]^{\prime}\right| d s \leq \int_{t_{1}}^{t_{2}} \psi(s) d s .
\end{aligned}
$$

The sequence $\left\{(1-t)\left(K_{P, Q} N x_{n}\right)^{\prime}(t)\right\}$ is therefore equicontinuous on $[0,1)$ and therefore converges to some (1 $t)\left(K_{P, Q} N x_{0}\right)^{\prime}(t) \in C[0,1]$ with $\lim _{t \rightarrow 1^{-}}(1-t)[(1-$ $\left.t)\left(K_{P, Q} N x_{n}\right)^{\prime}(t)\right]=0, t \in[0,1)$.

We then conclude that $K_{P, Q}$ is relatively compact and since $Q N(\bar{\Omega})$ is bounded we conclude from Definition 2 that $N$ is $L$-compact on every bounded subset $\Omega$ of $X$ and hence $N$ is $L$-completely continuous.

\section{Main Result}

In this section we will state and prove the main existence results for problem (1).

Theorem 7. Assume that the following conditions are satisfied:

(H1) There exists a positive constant $B_{1}$ such that, for each $x \in \operatorname{dom} L$, if $|x(t)|>B_{1}$ for all $t \in[0,1]$ then

QNx $(t)$

$=\frac{e^{t}}{h} \sum_{i=1}^{m=2} a_{i} \int_{\xi_{i}}^{1} \int_{0}^{s}\left[f\left(\tau, x(\tau), x^{\prime}(\tau)\right)+g(\tau)\right] d \tau d s$

$\neq 0$.

(H2) There exists a positive constant $B_{2}$ such that for $c \in \mathbb{R}$ and $|c|>B_{2}$ either $(i) \mathrm{QN}(c) \geq 0$ or $($ ii) $Q N(c) \leq 0$.

Then (1) has at least one solution in X provided

$$
\|a\|_{Z}+\|b\|_{1}<\frac{1}{2}
$$

To prove Theorem 7, we first establish some lemmas.

Lemma 8. Let $\Omega_{1}=\{x \in \operatorname{dom} L \backslash \operatorname{Ker} L: L x=\lambda N x, \lambda \in$ $(0,1)\}$ then $\Omega_{1}$ is bounded in $X$.

Proof. Let $x \in \Omega_{1}$. We let $L x=\lambda N x, 0<\lambda<1$. Since $\lambda \neq 0$ it is clear that $N x \in \operatorname{Im} L=\operatorname{Ker} Q$; hence $Q N x=0$ for all $t \in[0,1]$. Therefore by assumption (H1) there exist $t_{0} \in[0,1]$ such that $\left|x\left(t_{0}\right)\right|<B_{1}$. Now

$$
\begin{aligned}
\int_{0}^{t} \int_{0}^{s} x^{\prime \prime}(\tau) d \tau d s & =\int_{0}^{t_{0}}\left(t_{0}-s\right) x^{\prime \prime}(s) d s \\
& =x\left(t_{0}\right)-x(0) \\
\|P x\|_{X} & =|x(0)| \\
& =\left|x\left(t_{0}\right)+\int_{0}^{t_{0}}\left(t_{0}-s\right) x^{\prime \prime}(s) d s\right| \\
& \leq\left|x\left(t_{0}\right)\right|+\int_{0}^{1}(1-s)\left|x^{\prime \prime}(s)\right| d s \\
& \leq B_{1}+\|L x\|_{Z} \leq B_{1}+\|N x\|_{Z} .
\end{aligned}
$$

We note that $(I-P) x \in \operatorname{dom} L \cap \operatorname{Ker} P$ :

$$
\begin{aligned}
\|(I-P) x\|_{X} & =\left\|K_{P} L(I-P) x\right\|_{X} \leq\left\|K_{P} L x\right\|_{X} \\
& \leq\|L x\|_{Z}<\|N x\|_{Z} .
\end{aligned}
$$

From (41) and (42) we get

$$
\begin{aligned}
\|x\|_{X} & =\|P x+(I-P) x\|_{X} \leq\|P x\|_{X}+\|(I-P) x\|_{X} \\
& <B_{1}+2\|N x\|_{Z} .
\end{aligned}
$$

From the definition of $N$ we obtain

$$
\begin{aligned}
& \|N x\|_{Z}=\|(1-t)(N x)(t)\|_{1}=\int_{0}^{1}(1-t) \\
& \cdot\left[f\left(t, x(t), x^{\prime}(t)\right)+g(t)\right] d t \\
& \leq \int_{0}^{1}\left[(1-t) a(t)|x(t)|+|b(t)|(1-t) x^{\prime}(t)\right. \\
& +(1-t)|r(t)|+(1-t)|g(t)|] d t \leq\|a\|_{Z} \\
& \cdot\|x\|_{\infty}+\|b\|_{1}\left\|(1-t) x^{\prime}\right\|_{\infty}+\|r\|_{Z}+\|g\|_{Z} .
\end{aligned}
$$

From (43) and (44) we get

$$
\begin{aligned}
\|x\|_{X}< & B_{1} \\
& +2\left[\|a\|_{Z}\|x\|_{X}+\|b\|_{1}\|x\|_{X}+\|r\|_{Z}+\|g\|_{Z}\right] .
\end{aligned}
$$

Since $1-2\left[\|a\|_{Z}+\|b\|_{1}\right]>0$ we obtain that

$$
\|x\|_{X}<\frac{B_{1}+2\|r\|_{Z}}{1-2\left[\|a\|_{Z}+\|b\|_{1}\right]}+\frac{2\|g\|_{Z}}{1-2\left[\|a\|_{Z}+\|b\|_{1}\right]} .
$$

Therefore $\Omega_{1}$ is bounded in $X$.

Lemma 9. The set $\Omega_{2}=\{x \in \operatorname{Ker} L: N x \in \operatorname{Im} L\}$ is $a$ bounded subset of $X$.

Proof. Let $x \in \Omega_{2}$ with $x(t)=c, c \in \mathbb{R}$. Then $Q N(c)=0$ implies $N(c) \in \operatorname{Im} L=\operatorname{Ker} Q$. We therefore derive from (H2) that

$$
\|x\|_{X}=|c|=\max \{|c|,\|(1-t) 0\|\}=|c|<B_{2} .
$$


Lemma 10. The sets $\Omega_{3}^{+}=\{x \in \operatorname{Ker} L: \lambda x+(1-\lambda) Q N x=$ $0, \lambda \in[0,1]\}$ and $\Omega_{3}^{-}=\{x \in \operatorname{Ker} L:-\lambda x+(1-\lambda) Q N x=$ $0, \lambda \in[0,1]\}$ are bounded in X provided (H2)(i) and (H2)(ii) are satisfied simultaneously.

Proof. If $Q N(c) \geq 0$ then, for $x \in \Omega_{3}^{+}$with $x(t)=c, c \in \mathbb{R}$, we have

$$
\lambda c=-(1-\lambda) Q N(c) .
$$

If $\lambda=0$, it follows from (48) that $N(c) \in \operatorname{Ker} Q=\operatorname{Im} L$; that is, $N(c) \in \Omega_{2}$, and therefore by Lemma 9. we have $\|x\|_{X} \leq B_{2}$. However if $\lambda \in(0,1)$ and $\|c\|>B_{2}$ then using assumption (H2)(i) we obtain the contradiction

$$
\lambda c^{2}=-(1-\lambda) c Q N(c) \leq 0 .
$$

Thus $\|x\|_{X}=|c|<B_{2}$. Hence $\Omega_{3}^{+}$is bounded in $X$. We can use the same argument to prove that $\Omega_{3}^{-}$is also bounded in $X$.

Proof of Theorem 7 . We show that the conditions of Theorem 3 are satisfied where $\Omega$ is an open and bounded set such that $\bigcup_{i=1}^{3} \Omega_{i} \subset \Omega$. It is easily seen that conditions (i) and (ii) of Theorem 3 are satisfied by using Lemmas 8 and 9. To verify the third condition we set $H(x, \lambda)= \pm \lambda x+(1-\lambda) Q N x$. We choose the isomorphism $J: \operatorname{Im} Q \rightarrow \operatorname{Ker} L$ defined by $J(c)=c, c \in \mathbb{R}$. By Lemma 10, we derive that $H(x, \lambda) \neq 0$ for all $(x, \lambda) \in(\operatorname{Ker} L \cap \partial \Omega) \times[0,1]$. Hence

$$
\begin{aligned}
& \operatorname{deg}\left(\left.Q N\right|_{\operatorname{Ker} L}, \Omega \cap \operatorname{Ker} L, 0\right) \\
& =\operatorname{deg}( \pm J, \Omega \cap \operatorname{Ker} L, 0) \neq 0 .
\end{aligned}
$$

Therefore problem (1) has at least one solution in $X$.

\section{Conflicts of Interest}

The authors declare that there are no conflicts of interest regarding the publication of this paper.

\section{Acknowledgments}

This work is supported by the Covenant University Centre for Research, Innovation and Discovery (CUCRID).

\section{References}

[1] C. P. Gupta, S. K. Ntouyas, and P. C. Tsamatos, "Solvability of an $m$-point boundary value problem for second order ordinary differential equations," Journal of Mathematical Analysis and Applications, vol. 189, no. 2, pp. 575-584, 1995.

[2] R. Ma and D. O'Regan, "Solvability of singular second order $m$-point boundary value problems," Journal of Mathematical Analysis and Applications, vol. 301, no. 1, pp. 124-134, 2005.

[3] R. P. Agarwal and D. O'Regan, Singular Differential and Integral Equations with Applications, Kluwer Academic Publishers, London, UK, 2003.

[4] H. Asakawa, "Nonresonant singular two-point boundary value problems," Nonlinear Analysis: Theory, Methods \& Applications, vol. 44, no. 6, pp. 791-809, 2001.
[5] G. Infante and M. a. Zima, "Positive solutions of multi-point boundary value problems at resonance," Nonlinear Analysis: Theory, Methods \& Applications, vol. 69, no. 8, pp. 2458-2465, 2008.

[6] N. Kosmatov, "A singular non-local problem at resonance," Journal of Mathematical Analysis and Applications, vol. 394, no. 1, pp. 425-431, 2012.

[7] R. Ma, "Existence of positive solutions for superlinear semipositone $m$-point boundary-value problems," Proceedings of the Edinburg Mathematics Society, vol. 46, no. 2, pp. 279-292, 2003.

[8] D. O’Regan, Theory of Singular Boundary Value Problems, World Scientific, River Edge, NJ, Usa, 1994.

[9] Z. Zhang and J. Wang, "The upper and lower solution method for a class of singular nonlinear second order three-point boundary value problems," Journal of Computational and Applied Mathematics, vol. 147, no. 1, pp. 41-52, 2002.

[10] J. Mawhin, Topological Degree Methods in Nonlinear Boundary Value Problems, vol. 40 of NSFCBMS Regional Conference Series in Mathematics, American Mathematical Society, Providence, RI, USA, 1979. 


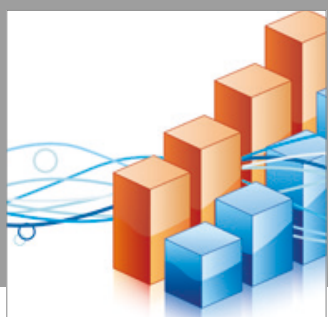

Advances in

Operations Research

vatersals

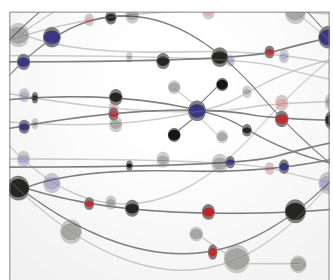

\section{The Scientific} World Journal
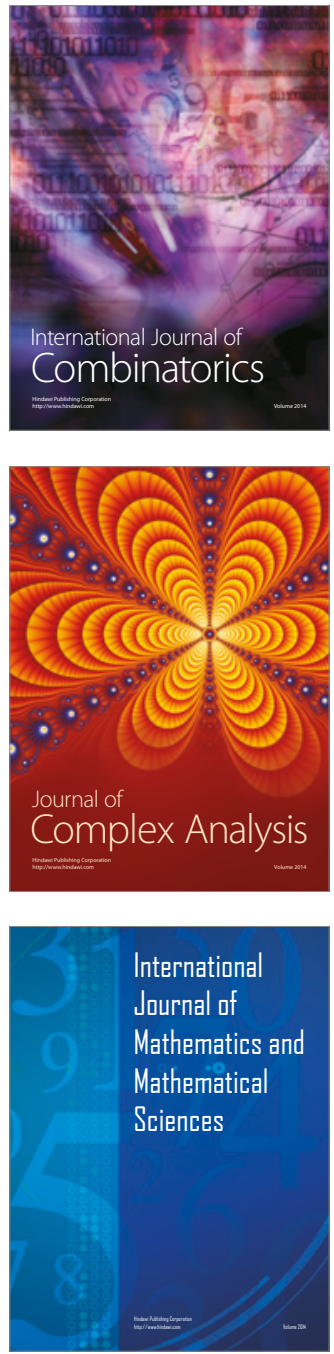
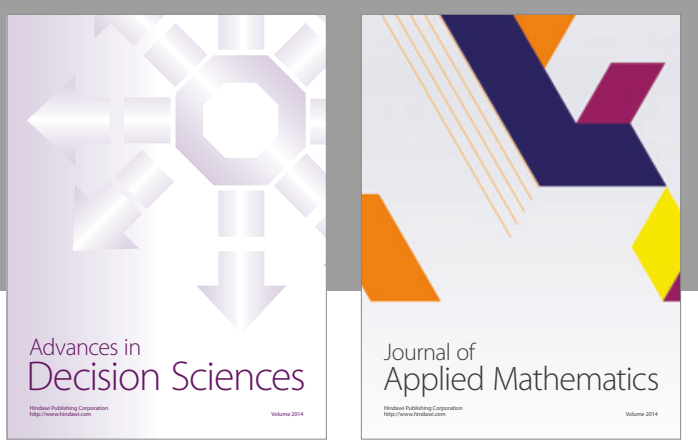

Algebra

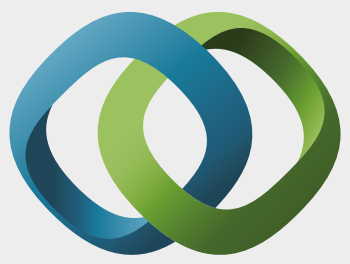

\section{Hindawi}

Submit your manuscripts at

https://www.hindawi.com
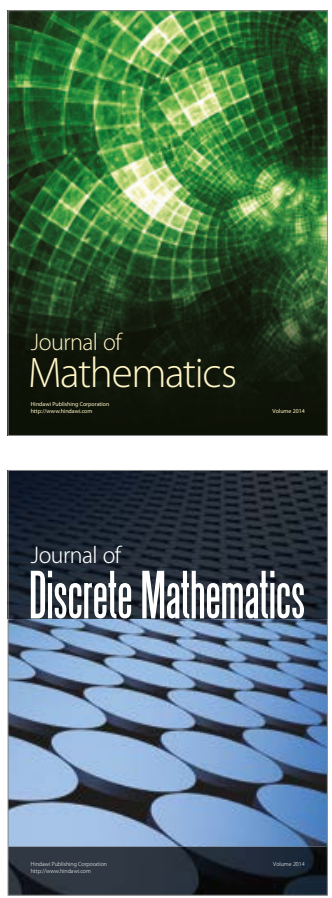

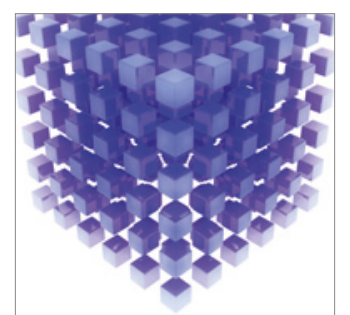

Mathematical Problems in Engineering
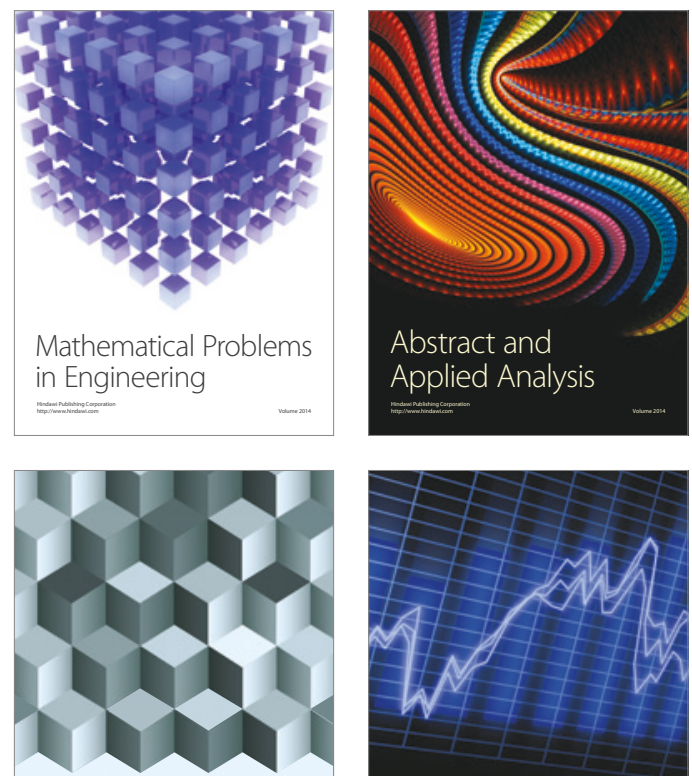

Journal of

Function Spaces

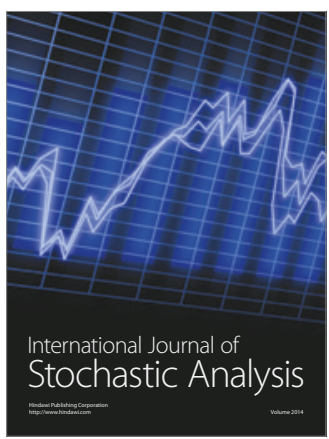

Probability and Statistics
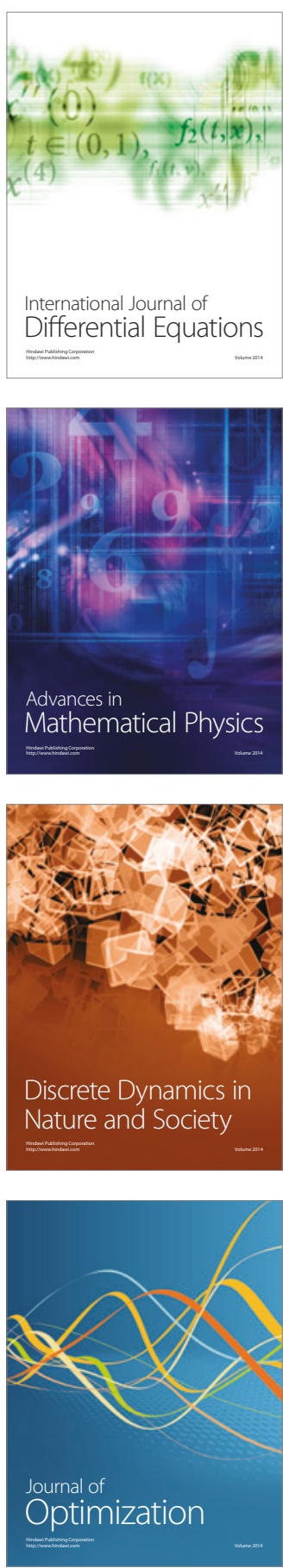